\title{
Small-strain properties of soft clay treated with fibre and cement
}

\author{
B. Fatahi ${ }^{1}$, B. Fatahi ${ }^{2}$, T. M. Le ${ }^{3}$ and H. Khabbaz ${ }^{4}$ \\ ${ }^{1}$ Senior Lecturer in Geotechnical Engineering, School of Civil and Environmental Engineering, \\ University of Technology Sydney (UTS), Sydney, Australia, Telephone: +61 (2) 95147883 , \\ Telefax: +61 (2) 9514 2633, E-mail: behzad.fatahi@uts.edu.au \\ ${ }^{2}$ Research Assistant, School of Civil and Environmental Engineering, University of Technology Sydney \\ (UTS), Sydney, Australia, Telephone: +61 (2) 9514 9095, Telefax: +61 (2) 9514 2633, \\ E-mail: behnam.fatahi@uts.edu.au \\ ${ }^{3}$ PhD Candidate, School of Civil and Environmental Engineering, University of Technology Sydney \\ (UTS), Sydney, Australia, Telephone: +61 (2) 9514 9218, Telefax: +61 (2) 9514 2633, \\ E-mail:Thu.Le@uts.edu.au \\ ${ }^{4}$ Associate Professor of Geotechnical Engineering, School of Civil and Environmental Engineering, \\ University of Technology Sydney (UTS), Sydney, Australia, Telephone: +61 (2) 9514 9942, \\ Telefax: +61 (2) 9514 2633, E-mail: Hadi.Khabbaz@uts.edu.au
}

Received 10 September 2012, revised 21 May 2013, accepted 15 June 2013

\begin{abstract}
To improve the dynamic properties of soft soil, the cement treatment technique combined with fibre reinforcement can be employed. In this study, the effects of two types of fibres (polypropylene and recycled carpet) on the hardening process and small-strain properties of cement-treated kaolinite and bentonite clays are investigated. Cement-treated clay specimens were prepared using cement contents of $5 \%, 10 \%$ and $15 \%$ by weight of dry soil for the kaolinite samples, and $30 \%, 40 \%$ and $50 \%$ for the bentonite samples. To investigate and understand the influence of different fibre types and contents, three different percentages of fibre content were adopted: $0.1 \%, 0.2 \%$ and $0.5 \%$ polypropylene fibres, and $0.5 \%, 0.75 \%$ and $1 \%$ carpet fibres. The results of bender element tests on 126 cylindrical samples of cement-treated clay with various cement and fibre contents were analysed to discern the relationships between fibre and cement content and the small-strain mechanical properties, including the shear wave velocity and maximum small-strain shear modulus of the treated soil. The influence of fibres and cement contents on the hardening time of treated soil has also been investigated.
\end{abstract}

KEYWORDS: Geosynthetics, Polypropylene fibre, Carpet fibre, Cement-treated clay, Shear wave velocity, Small-strain shear modulus

REFERENCE: Fatahi, B., Fatahi, B., Le, T. M. \& Khabbaz, H. (2013). Small-strain properties of soft clay treated with fibre and cement. Geosynthetics International, 20, No. 4, 286-300. [http://dx.doi.org/10.1680/gein.13.00018]

\section{INTRODUCTION}

In Australia, landfills are relied upon for disposal of wastes. As reported by Green Capital (2011), each year approximately 18 million tonnes of wastes from the municipal, construction, demolition, commercial and industrial sectors are disposed (landfills) in Australia. Textile waste in landfills contributes to the formation of leachate as it decomposes, which has the potential to contaminate groundwater. If waste generation grows at $4.5 \%$ per year, Australia will generate more than 81 million tonnes of waste in 2020-2021, of which a significant portion comprises polypropylene, old carpets and scrap metal waste materials (Australian National Waste Report 2010; Green Capital 2011). One of the practical solutions to overcome the environmental problems generated by these waste productions is to convert them to synthetic fibres specifically engineered as an additive to enhance materials performance.

Although a substantial amount of research has been carried out on sandy or clayey soils reinforced with waste fibres, there is a lack of study on the effect of fibres on the mechanical properties (particularly the small-strain properties) of cement-treated clays, which may be utilised in deep soil mixing. According to 
Consoli et al. (2007), the unconfined compression strength of sandy soils is significantly improved by cement stabilising, since the addition of $7 \%$ of cement can enhance the peak strength to about 3.2 MPa. In an investigation on the stiffness of cemented Bangkok clay, Piriyakul and Pochalard (2012) suggested that the replacement of fly ash in the range $15-20 \%$ at $20 \%$ cement content can achieve improved values of the undrained shear strength, shear wave velocity and initial shear modulus of stabilised soils compared with those of cemented soils with $0 \%$ fly ash replacement. Based on a study of the very-small-strain behaviour of cemented soils, Trhlíková et al. (2012) concluded that the shear modulus of stabilised soils was controlled by cementation, and was independent of the mean effective stress until the yield stress was reached. After yielding, the shear modulus of cemented soils increases with an increase in the mean stress, but has a higher value compared with the uncemented soils.

According to the results of bender element tests on cemented bentonite and cemented attapulgite, Fam and Santamarina (1996) concluded that the addition of cement produces significant changes in the shear velocity of the soils. A cement content of $10 \%$ can double the shear wave velocity of bentonite soils, and a bentonite:cement ratio of $1: 1$ caused the shear wave velocity to reach $120 \mathrm{~m} / \mathrm{s}$, compared with $10 \mathrm{~m} / \mathrm{s}$ for uncemented bentonite. The results for cemented attapulgite were similar to those for cemented bentonite, although the increase in the shear wave velocity of the attapulgite mixture was not as great as that of the bentonite mixture. Therefore Fam and Santamarina (1996) suggested that the shear velocity of the cemented clay increases as a result of three simultaneous processes: (1) an increase in the effective stress during the consolidation process; (2) a decrease in double-layer repulsion; and (3) an increase in rigidity due to the cementation process.

For fibre-reinforced soils without cement, the improvements of clay soil properties when reinforced by $5 \%$ of fibre content were observed to be $50 \%$ (from $160 \mathrm{kPa}$ to $240 \mathrm{kPa}$ ) for the unconfined compressive strength, and $100 \%$ (from $4 \mathrm{GPa}$ to $8 \mathrm{GPa}$ ) for the stiffness (Al-Akhras 2003). However, Heineck et al. (2005) reported that the addition of fibres has no influence on the stiffness of the soils under very small shear strains, but can significantly affect the lateral displacements at very large shear strains.

If the mechanical characteristics of cement-treated soils can be improved by introducing waste fibres, two goals can be achieved simultaneously: a reduction of the cement content needed to achieve the required material properties, and the utilisation of waste materials, to reduce the demands placed on our already teeming landfills. In this study, following a brief review of current literature on the application of fibres in geotechnical engineering, the effects of two target fibres (polypropylene and recycled carpet) on the small-strain mechanical properties of cement-improved kaolinite and bentonite clays are investigated, based on bender element test results.

\section{FIBRE-REINFORCED SOIL}

Polypropylene fibres are commonly used in the concrete industry as an additive to improve strength and reduce cracking and spalling. The purpose of adding polypropylene fibres to concrete is not to substitute for the steel reinforcement, but to reduce the formation of micro cracks. The primary attraction is that of low cost (Moncrieff 1975).

Jiang et al. (2010) reported the results of adding discrete polypropylene fibres on the engineering properties of soil. It was shown that the unconfined compressive strength, cohesion and internal friction angle of soil reinforced with polypropylene fibres showed an initial increase, followed by a decrease with further increase in fibre content. The optimum polypropylene fibre content was determined to be $0.3 \%$ by weight of the nonreinforced soil. Al-Refeai (1991) reported that fibrillated polypropylene fibres outperformed glass fibres, and the optimum fibre length was $76 \mathrm{~mm}$ for sands. Morel and Gourc (1997) recommended an optimum mesh content of $0.5 \%$ dry weight of sand for discrete polypropylene mesh elements.

Consoli et al. (2003) employed polypropylene fibres with different lengths and diameters at various fibre contents to reinforce sandy soil. They concluded that the deviatoric stress of the reinforced soil specimen increased with an increase in fibre length, fibre aspect ratio and fibre content, whereas it decreased with an increase in fibre diameter alone. In addition, test results reported by Edinçliler and Cagatay (2013) revealed that the aspect ratio of the fibres influences the properties of fibrereinforced sand significantly, and there is an optimum aspect ratio that results in an increased California bearing ratio (CBR) of the improved soil, and consequently a decreased design thickness of the pavement.

Investigations by Cai et al. (2006) found that the introduction of polypropylene fibres into soil improved the engineering properties (specifically the shear strength and toughness). Their investigation also found that the extent of the strength improvement contributed by fibre introduction was not affected by curing time.

Investigations by Sahin (2009) and Cai et al. (2006) showed that the most significant effect, which increased with polypropylene content, was on ductility, with specimens with a higher polypropylene content failing at a far greater strain.

Miller and Rifai (2004) found that that the inclusion of polypropylene fibres reduced crack formation and the hydraulic conductivity of compacted clay soil. They observed a slight effect on the compaction behaviour of the fibrous soil due to fibre inclusion, and concluded that the optimum fibre content that was necessary to achieve the maximum crack reduction, the maximum dry density, and an acceptable hydraulic conductivity, within the range of mixing workability, was between $0.4 \%$ and $0.5 \%$.

Yetimoglu et al. (2005) conducted an experimental study on the CBR of soil, and showed that the presence of polypropylene fibres (Duomix F20) in sand fill caused an appreciable increase in the peak piston load and the 
brittleness of the system, providing a higher loss of postpeak strength. They concluded that the initial stiffness was slightly affected by the fibre inclusions. Furthermore, Kumar and Kaur (2012) observed a significant increase in the ultimate bearing capacity of a footing resting on a fibre-reinforced sand bed by analysing the pressuresettlement response from a steel plate load test.

There are established recycling options for a small proportion of carpet waste: carpet tiles are recycled by separating the nylon fibres from the bitumen backing; mixed synthetic carpet is shredded, and mixed with rubber crumb and sand, to form a surface for equestrian ménages; and carpet fibres are pulled, and blended with other fibres to produce products such as underlay and insulation (www.carpetrecyclinguk.com). One of the methods for reusing these recycled wastes is to apply them as reinforcement. Wang (1999) reported the benefits of using carpet fibres for soil reinforcement, and concluded that the confined compressive strength and residual strength the of soil increase. Field tests showed that shredded carpet waste fibres up to $70 \mathrm{~mm}$ long can be mixed into soil with standard equipment. According to Miraftab and Lickfold (2008), nylon carpet pile waste can be successfully mixed with substandard soil up to a maximum of $10 \%$, enhancing both the cohesion and strength of the soil and its internal friction. Michalowski and Cermak (2003) reported that the addition of a small amount of synthetic fibre increases the failure stress of the soil-fibre composite. Wang et al. (1994) investigated the relationship between the tensile strength of concrete with varying carpet fibre contents, and concluded that the presence of carpet fibre reinforcement improves the tensile strength, toughness, and reduces the drying shrinkage.

The clay samples used for testing in this study were Q38 kaolinite clay and ActiveBond23 bentonite. Kaolinite and bentonite were selected, as they are artificial clays with significantly different properties. The kaolinite samples had an average liquid limit of $50 \%$, compared with $340 \%$ for the bentonite samples. Q38 kaolinite clay is a dry-milled kaolin China clay, of a white-cream colour. Kaolinite is one of the most abundant minerals in soil, and as such is often encountered in in-situ conditions. Kaolinite is formed by the breakdown of feldspar, induced by water and carbon dioxide, and is often formed by the alteration of aluminium silicate minerals in a warm, humid environment (Murray 1999; Craig 2000). ActiveBond 23 is a pure form of bentonite, which is plastic and impermeable, has a high absorbing and swelling capacity, and is highly viscous when suspended in water. Common uses of bentonite include diaphragm wall construction, piling, tunnelling, dam sealing and waste containment. The high swelling properties of bentonite on exposure to water facilitate the sealing of porous soils and leaking dams. The admixture used in stabilising the experimental clay samples was Type I Portland cement, one of the most widely used construction materials in Australia. Type I Portland cement was chosen as it is representative of a typical cement used in chemical stabilisation in Australia. In the design of a soil-cement mix, the cement content is the fundamental variable to be adjusted when considering the required strength of the composite mixture. Higher cement contents generally result in increased strength, durability and permeability characteristics. The exact cement content is dependent both on the site requirements and on the type of soil being stabilised. Soils of differing compositions react differently to cementious additives, and therefore designs are specific to in-situ conditions. Cement contents of $10 \%, 15 \%$ and $20 \%$ of the dry weight of the clay were adopted for the kaolinite samples, together with a water content of $150 \%$ of the clay's liquid limit; these values similar to those used in the mixes by Lorenzo and Bergado (2004) and Fatahi et al. (2012). Cement contents of $30 \%, 40 \%$ and $50 \%$ of the dry weight of the clay were adopted for the bentonite samples, together with a water content of $110 \%$ of the clay liquid limit.

For this study, $0.1 \%, 0.2 \%$ and $0.5 \%$ polypropylene fibres, and $0.5 \%, 0.75 \%$ and $1 \%$ carpet fibres, were used to reinforce the cement-stabilised clay, producing 108 samples (three samples per mix) for the bender element tests, together with 18 control samples without fibre reinforcement. This gave a total of 63 samples per fibre type. The quantities of fibre and cement were expressed as percentages of the dry weight of the clay. Table 1 summarises the mixes used in this study.

The polypropylene fibres used in this research are $18 \mathrm{~mm}$ Sika monofilament fibres with nominal diameter, density and Young's modulus of $22 \mu \mathrm{m}, 0.91 \mathrm{~g} / \mathrm{ml}$ and $3.5 \mathrm{GPa}$, respectively. Monofilament polypropylene fibre was used rather than fibrillated fibre to prevent any clustering or tangling during the mix, and hence allowed for a more homogeneous mix. A greater fibre content (e.g. more than $0.5 \%$ polypropylene fibre) in the mixture results in low workability, and prevents homogeneous mixing. Thus various fibre contents were selected, after considering investigations published in the literature and the workability of mixes in the laboratory. The carpet fibres used in this study were from polypropylene tufted carpets, granulated at $10 \mathrm{~mm}$ size in the UK. They were collected from some edge trims from the carpet manufacturing process, and were then granulated by one of the machine suppliers, such as Cumberland, using a $10 \mathrm{~mm}$ screen. Figure 1 shows the various fibres used in this study.

\section{EXPERIMENTAL PROCEDURE}

The clay and fibres were initially mixed thoroughly, with water added and mixing conducted to obtain reasonable workability. For the kaolinite a water content of $75 \%$, which is $50 \%$ more than the liquid limit of the soil, was required to produce a mix with adequate workability. For the bentonite, the mixture was overly aqueous at a water content of $510 \%$, which is $50 \%$ more than the liquid limit of bentonite. Thus a water content of $374 \%$ (10\% more than the liquid limit of bentonite) was adopted for the bentonite sample preparation. Cement slurry with a water:cement ratio of $1: 1$ was then added to the remoulded reinforced clay as the stabilising admixture. Alternate hand and mechanical mixing were introduced to ensure that a homogeneous mix was produced for all samples. 
Table 1. Summary of mixes used in this study

\begin{tabular}{|c|c|c|c|c|c|}
\hline Test type & Soil type & Cement content $(\%)$ & Fibre type & Fibre content (\%) & Mix no. \\
\hline $\begin{array}{l}\text { Bender element } \\
\text { (Shear wave velocity) }\end{array}$ & Kaolinite & $\begin{array}{l}30 \\
\\
40 \\
50\end{array}$ & $\begin{array}{l}- \\
\text { Polypropylene } \\
\text { Recycled carpet } \\
- \\
\text { Polypropylene } \\
\text { Recycled carpet } \\
- \\
\text { Polypropylene } \\
\text { Recycled carpet } \\
\text { Polypropylene } \\
\text { Recycled carpet } \\
\text { Polypropylene } \\
\text { Polypropylene } \\
\text { Recycled carpet } \\
\end{array}$ & $\begin{array}{l}- \\
0.1 \\
0.2 \\
0.5 \\
0.5 \\
0.75 \\
1.0 \\
- \\
0.1 \\
0.2 \\
0.5 \\
0.5 \\
0.75 \\
1.0 \\
- \\
0.1 \\
0.2 \\
0.5 \\
0.5 \\
0.75 \\
1.0 \\
- \\
0.1 \\
0.2 \\
0.5 \\
0.5 \\
0.75 \\
1.0 \\
- \\
0.1 \\
0.2 \\
0.5 \\
0.5 \\
0.75 \\
1.0 \\
- \\
0.1 \\
0.2 \\
0.5 \\
0.5 \\
0.75 \\
1.0\end{array}$ & $\begin{array}{r}1 \\
2 \\
3 \\
3 \\
4 \\
5\end{array}$ \\
\hline
\end{tabular}

The resulting mixtures were reasonably workable for placement into the moulds.

In an effort to minimise entrapped air and provide adequate compaction effort, the mixture was placed into the mould $(50 \mathrm{~mm}$ in diameter and $100 \mathrm{~mm}$ high) in several layers, and worked into the mould with palette knives. The moulds were then placed on a vibration table to ensure that entrapped air was minimised, and that the samples were uniform. Plastic sheets were wrapped round the final specimens to minimise moisture loss, and assist the cement hydration process. The specimens were left to cure within the moulds and plastic wrapping in a controlled environment for $24 \mathrm{~h}$ prior to de-moulding. The ambient temperature of the controlled environment was $25^{\circ} \mathrm{C}$ for all specimens. The specimens were placed in a curing bath immediately after the moulding and compaction processes, and remained in the curing bath during the testing period. After removal from the curing bath for testing, the weight and dimensions of the samples were measured.
The bender element test is a non-destructive test that has gained popularity in the laboratory determination of small-strain shear modulus. Bender elements are essentially a pair of piezoelectric transducers composed of two conductive outer electrodes, two ceramic plates, and a conductive metal shim at the centre. The ceramic plates are polarised, and made piezoelectric. When a bender element is deformed, the lattice distorts the dipole moment of the crystal, and a voltage is generated. Conversely, applying a voltage potential causes a bender element to deform. Hence bender elements can be used as either shear wave velocity or compression wave velocity sources or receivers. Bender elements couple well with soil, and mechanically similar bender elements operate in the same frequency range and are therefore tuned to each other. The bender element systems connect directly into a master control box, which in turn is connected to a PC running bender element control software. The bender element system employed in this study is manufactured to allow 


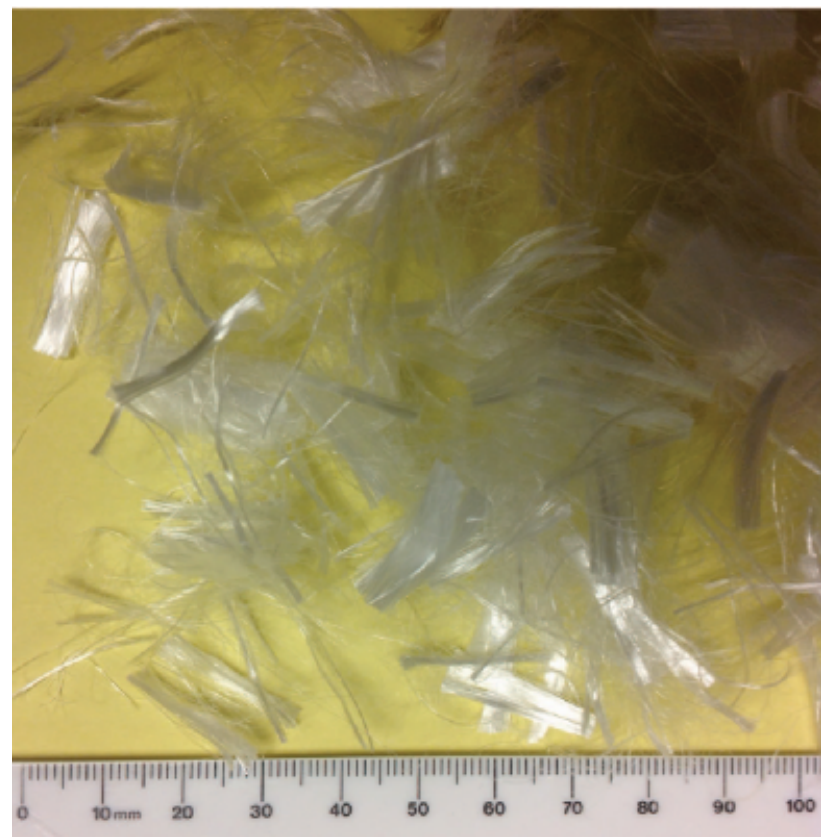

(a)

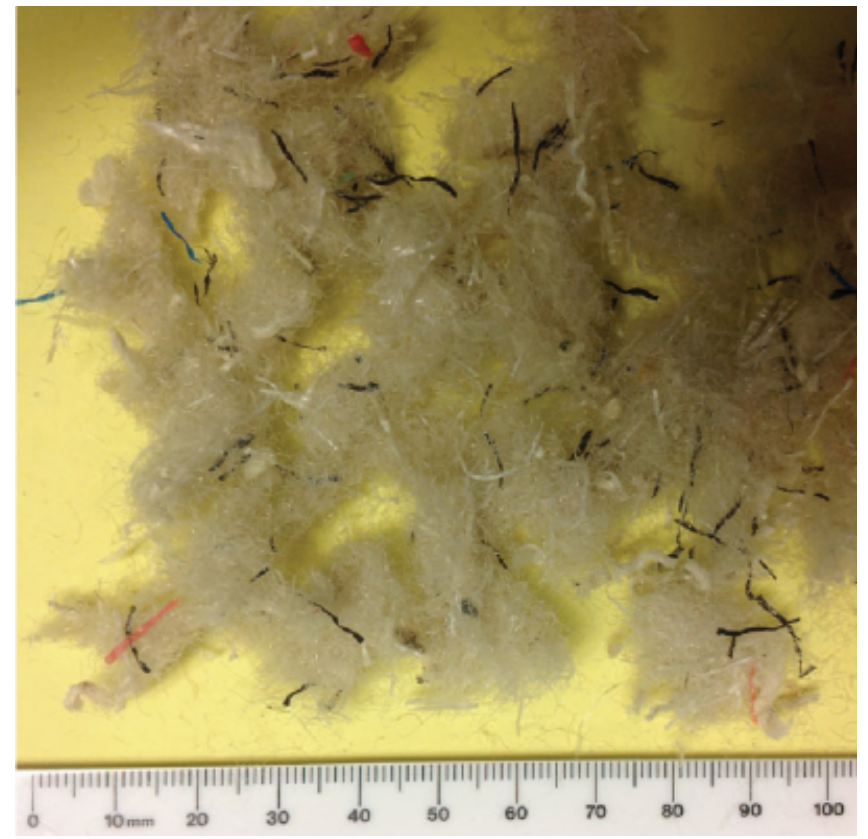

(b)

Figure 1. Types of fibre used in the study: (a) monofilament polypropylene fibres; (b) recycled carpet fibres

both shear wave and compression wave testing to be performed. It allows sine waves, square waves or any userdefined waves to be generated as the source signal type, and the amplitude, period and repeat time ( 0 to $60 \mathrm{~s})$ of the standard wave types can be controlled. The system used has a data acquisition speed of 2000000 samples per second, 16-bit resolution for data acquisition, and is connected to the control box through a USB link.

To carry out the bender element tests, the soil specimens were placed between bender elements (Figure 2), and the shear wave velocity of each soil specimen was obtained for different curing age by measuring the time required for the wave to travel between the two bender elements using a PC running GDS bender element control software (Figure 3). In this study, the propagated shear waves were sine waves, with an amplitude of $10 \mathrm{~V}$ and a period of $1 \mathrm{~s}$. This procedure was repeated for all the specimens over the testing period.

\section{RESULTS AND DISCUSSION}

Figures 4 and 5 show the results for shear wave velocity variations for 67 days' curing time for cement-treated kaolinite clay with carpet and polypropylene fibres, respectively. Although the shear wave velocity increases with cement content and curing time, the carpet fibre

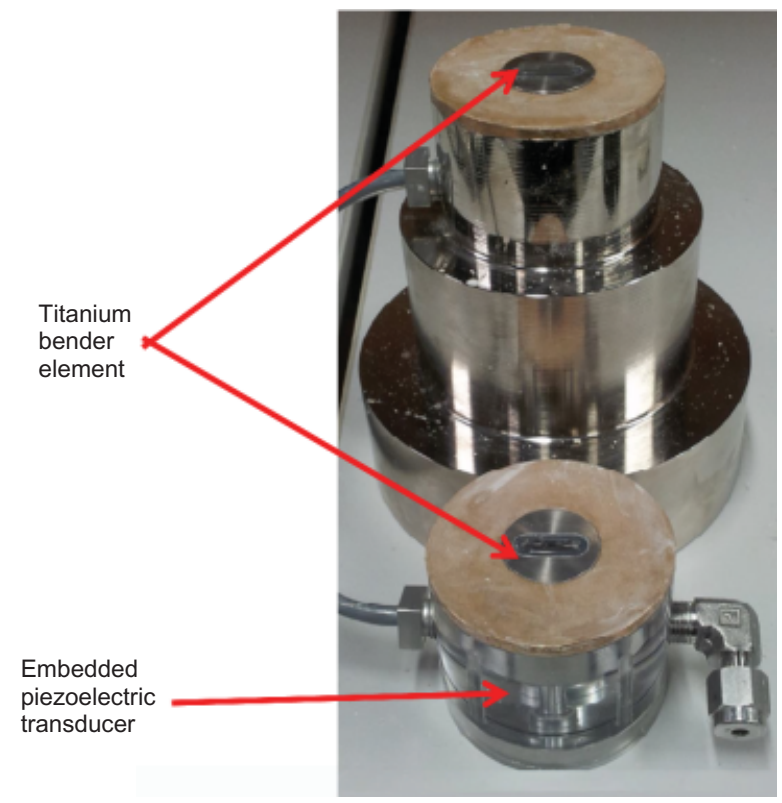

(a)

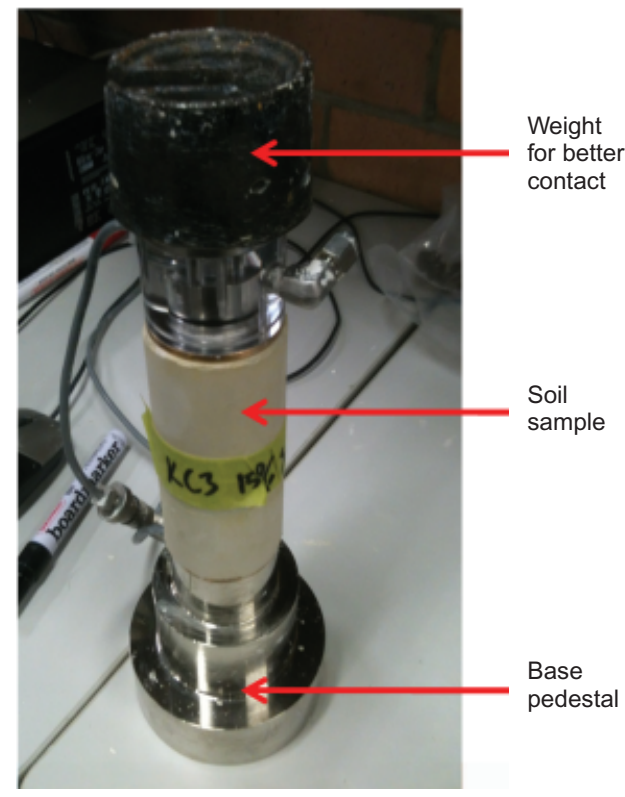

(b)

Figure 2. Bender element set-up: (a) bender element parts; (b) set-up during test

Geosynthetics International, 2013, 20, No. 4 


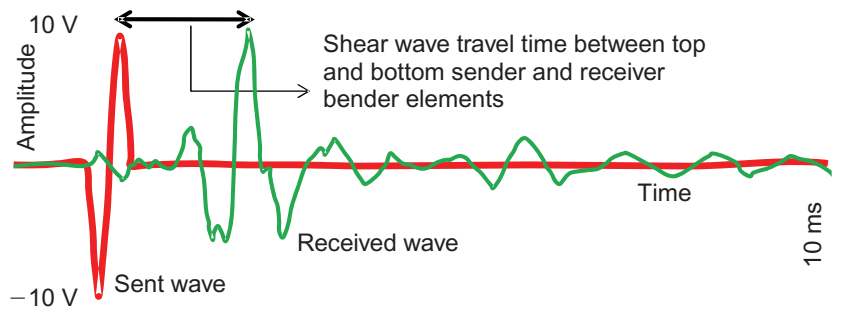

Figure 3. Schematic of signal processing to measure shear wave travel time between sender and receiver bender elements

addition contributes to a reduction in the shear wave velocity. The addition of $0.5 \%, 0.75 \%$ and $1 \%$ recycled carpet fibres contributes to a $6 \%, 16 \%$ and $23 \%$ reduction in the shear wave velocity of kaolinite treated with $20 \%$ cement. It can also be seen that the carpet fibre content influences the shear wave velocity more significantly when the soil is treated with a higher cement content. For example, the addition of $1 \%$ recycled carpet fibres induces a $10 \%, 20 \%$ and $30 \%$ reduction in the shear wave velocity of the treated soil with $28 \%, 31 \%$ and $38 \%$ cement content after 20 days, respectively. Irrespective of the cement content, the addition of $1 \%$ carpet fibres induces a reduction of approximately $25 \%$ in the shear wave velocity in the longer term (67 days). This may be a result of introducing a material that is more plastic than the cement-treated clay, and potentially does not engage very well with the surrounding matrix.

Figure 5 shows that the shear wave velocity increases with the polypropylene fibre content. The influence of the polypropylene fibre content on the shear wave velocity is more pronounced for the kaolinite clay treated with $20 \%$ cement. For example, the addition of $0.1 \%, 0.2 \%$ and $0.5 \%$ polypropylene fibres to the kaolinite clay treated with $20 \%$ cement induces a $23 \%, 33 \%$ and $52 \%$ increase in the shear wave velocity after 67 days' curing time.

In general, a higher cement content in the cementtreated soil results in greater heat development, accelerating the hydration and strengthening processes. As shown in Figures 4 and 5, the addition of cement content induces more heat, and thus the shear wave velocity increases with the cement content. Figures 6 and 7 show the variation of shear wave velocity of cement-treated bentonite with various cement contents and recycled carpet and polypropylene fibres, respectively.

Similar to the cement-treated kaolinite, the addition of carpet fibres and polypropylene fibres induces a decrease and an increase in the shear wave velocity of cementtreated bentonite, respectively. By adding 1\% recycled carpet fibres, the shear wave velocities of bentonite treated with $30 \%, 40 \%$ and $50 \%$ Portland cement decrease from $45.3 \mathrm{~m} / \mathrm{s}$ to $34.9 \mathrm{~m} / \mathrm{s}$ (a $23 \%$ reduction), $54.0 \mathrm{~m} / \mathrm{s}$ to $38.0 \mathrm{~m} / \mathrm{s}$ (a $29.6 \%$ reduction) and $72.7 \mathrm{~m} / \mathrm{s}$ to $41.7 \mathrm{~m} / \mathrm{s}$ (a $42.6 \%$ reduction), respectively. By contrast, the addition

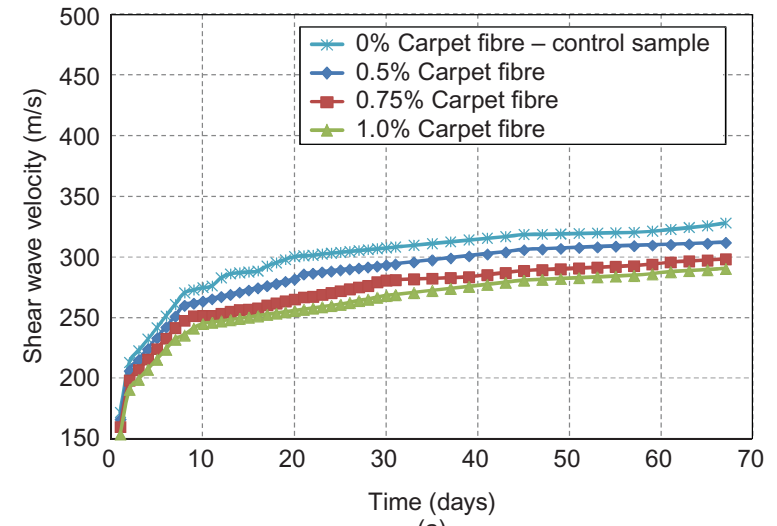

(a)

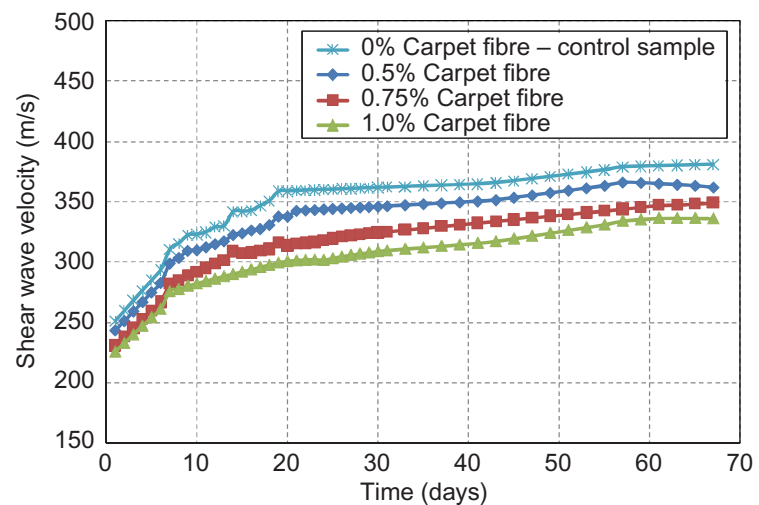

(b)

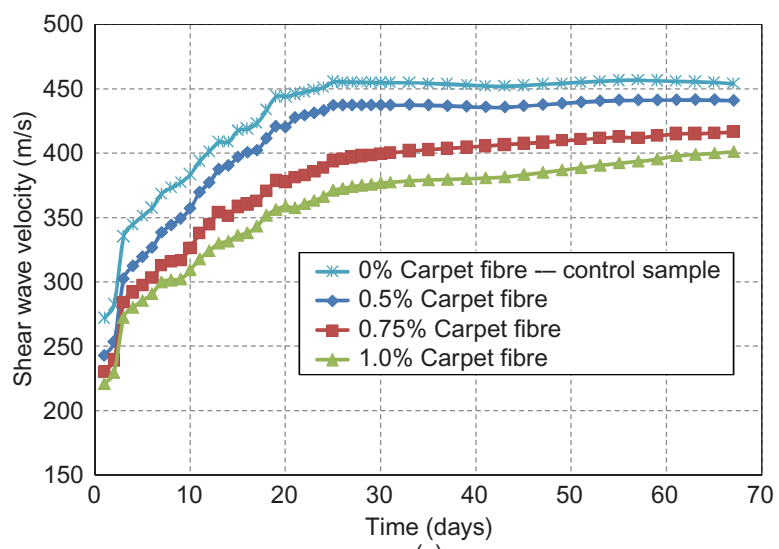

(c)

Figure 4. Variation of shear wave velocity with curing time for carpet-reinforced kaolinite treated with: (a) $10 \%$ cement; (b) $15 \%$ cement; (c) $20 \%$ cement 


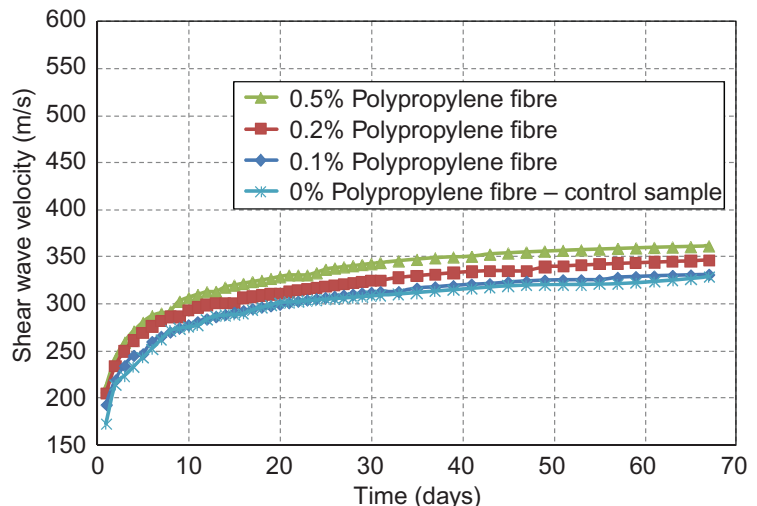

(a)

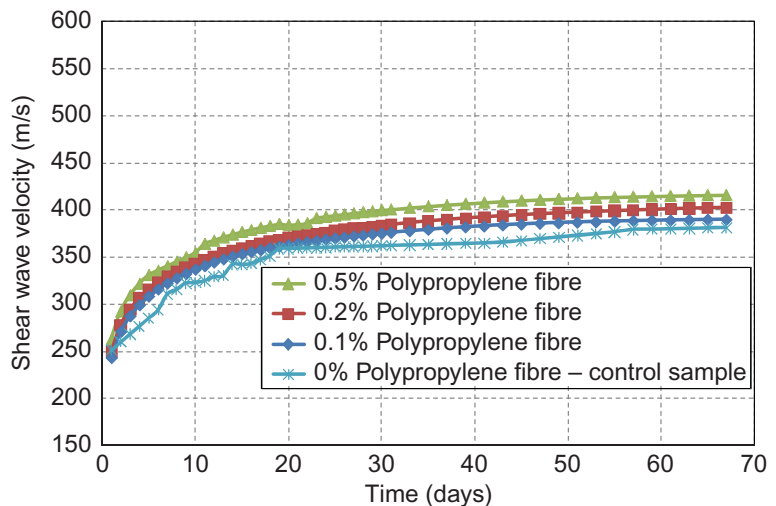

(b)

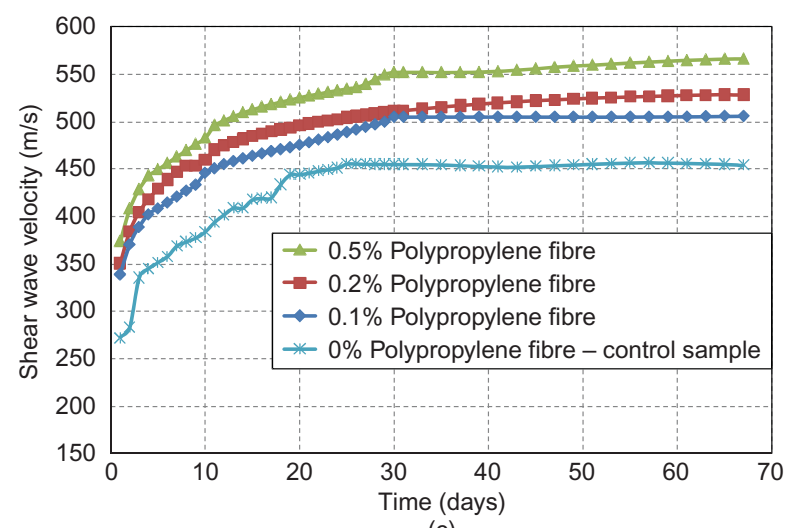

(c)

Figure 5. Variation of shear wave velocity with curing time for polypropylene-reinforced kaolinite treated with: (a) $\mathbf{1 0 \%}$ cement; (b) $15 \%$ cement; (c) $20 \%$ cement

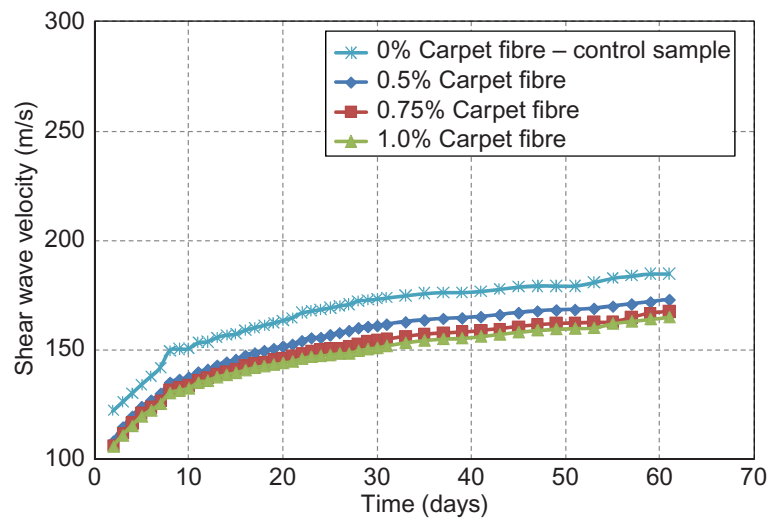

(a)

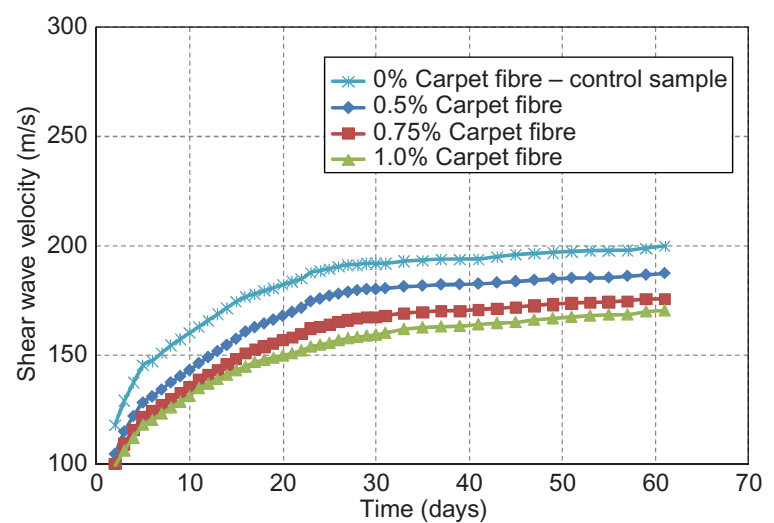

(b)

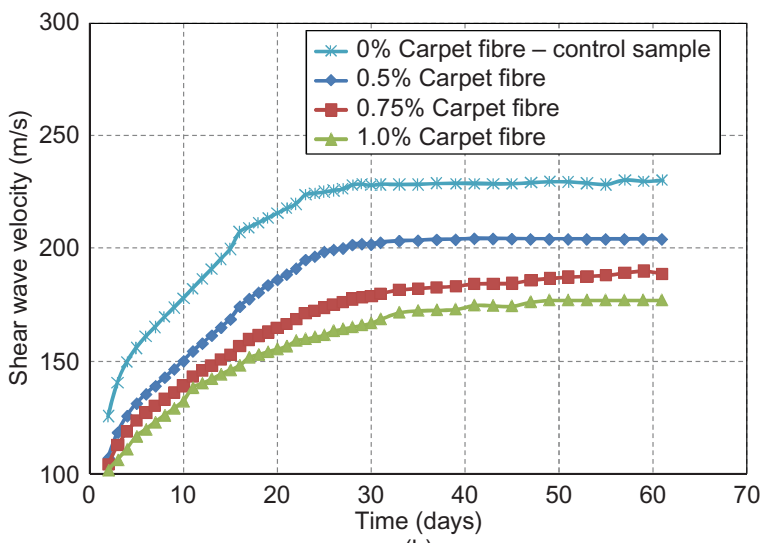

(b)

Figure 6. Variation of shear wave velocity with curing time for carpet-reinforced bentonite treated with: (a) $30 \%$ cement; (b) $40 \%$ cement; (c) $50 \%$ cement 


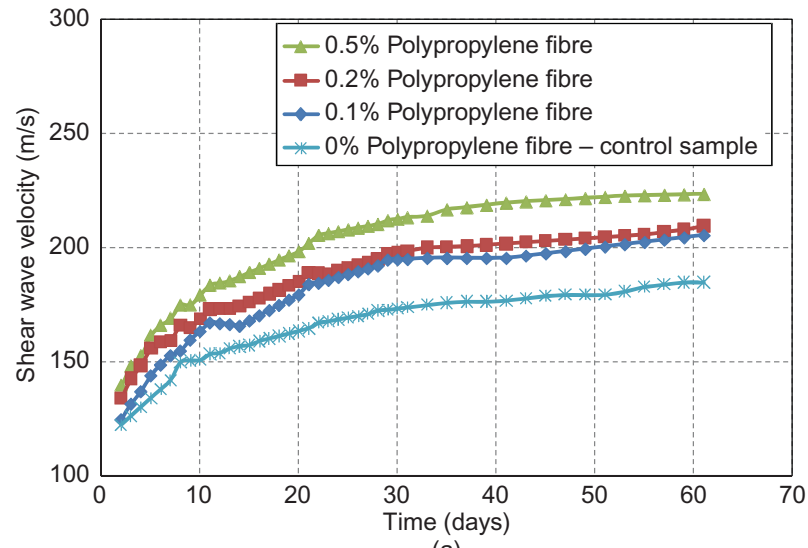

(a)

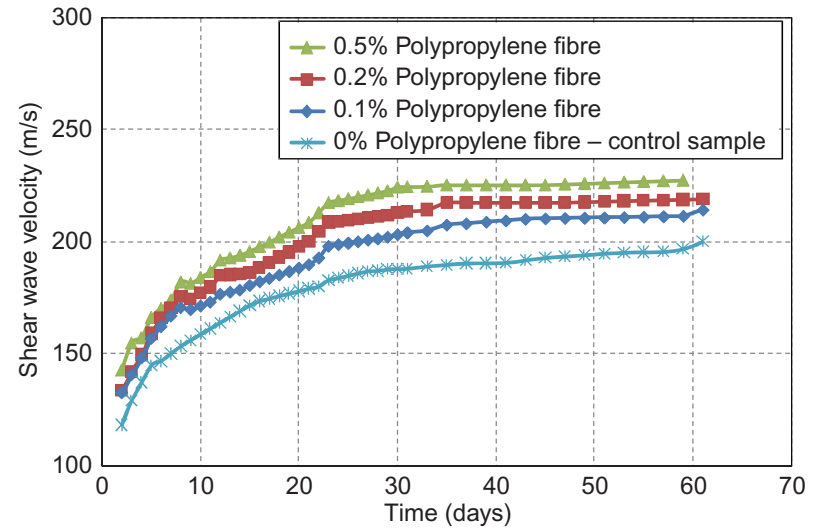

(b)

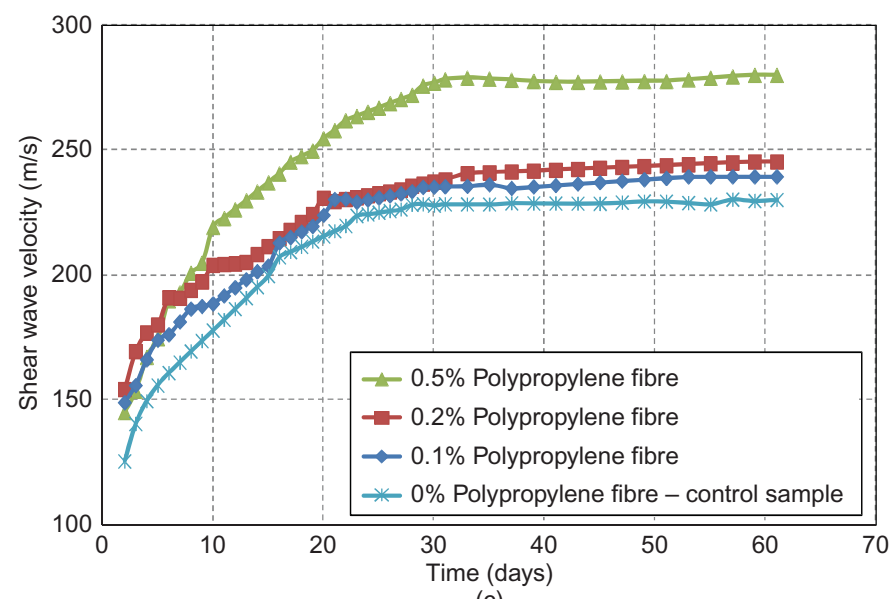

(c)

Figure 7. Variation of shear wave velocity with curing time for polypropylene-reinforced bentonite treated with: (a) $30 \%$ cement; (b) $40 \%$ cement; (c) $50 \%$ cement

of polypropylene fibres increases the shear wave velocity of the cement-treated bentonite. For example, the shear wave velocity of bentonite treated with $30 \%$ Portland cement increases by $21 \%, 26 \%$ and $42 \%$ with the addition of $0.1 \%, 0.2 \%$ and $0.5 \%$ polypropylene fibres, respectively.

Figure 8 summarises the time required to achieve $90 \%$ of the maximum recorded shear wave velocity. It is believed that the variations of shear wave velocity with time may correspond to the hardening or strengthening process of the cement-treated soil. Thus the results presented in Figures $8 \mathrm{a}-8 \mathrm{~d}$ give an indication of the influence of cement content and fibre content on the hardening process.

Referring to Figure 8, the time required to achieve $90 \%$ of the recorded shear wave velocity of cement-treated soil increases with carpet fibre content, but decreases with cement content. It is believed that the addition of carpet fibres reduces the available water content, as the fibres absorb water from the mix, resulting in a reduction in the water:cement ratio in the mix. Consequently, as for concrete, a reduction in the water:cement ratio while the cement content is kept constant reduces the microstructural space and water available for hydration of the cement, resulting in a decreased rate of heat development and increased time required for the hardening process, as evident in Figures 8a and 8c. Furthermore, when compar- ing mixes with equal fibre content, the addition of cement content leads to a smaller water: cement ratio, generating greater heat, and consequently the hydration process would be accelerated and the time required for the hardening process would decrease, as observed in Figures $8 \mathrm{a}-8 \mathrm{~d}$. According to Figures $8 \mathrm{~b}$ and $8 \mathrm{~d}$, the addition of polypropylene fibres has an insignificant effect on the hardening process, as polypropylene fibres do not absorb much water during the hydration process in the mix.

Figures 9-12 summarise the variations of the wet unit weight of the clay samples with the cement content, fibre content and time. Similar patterns of variation have been observed for the carpet- and polypropylene-treated soils. Although the samples were left in the curing/saturation bathtub, the surface of the samples was dried immediately after removal from the bathtub to measure the weight and the shear wave velocity.

According to Figures 9-12, the addition of fibres reduces the wet unit weight to some extent, whereas the unit weight of the treated soil increases slightly with cement content and time. For example, for kaolinite with $1 \%$ carpet fibres, the corresponding wet unit weights of soil samples treated with $10 \%, 15 \%$ and $20 \%$ cement content after 67 days are $14.7 \mathrm{kN} / \mathrm{m}^{3}, 14.9 \mathrm{kN} / \mathrm{m}^{3}$ and $15.1 \mathrm{kN} / \mathrm{m}^{3}$, respectively. The corresponding values for bentonite treated with $30 \%, 40 \%$ and $50 \%$ cement content are $12.5 \mathrm{kN} / \mathrm{m}^{3}, 12.8 \mathrm{kN} / \mathrm{m}^{3}$ and $13.1 \mathrm{kN} / \mathrm{m}^{3}$. It is believed 


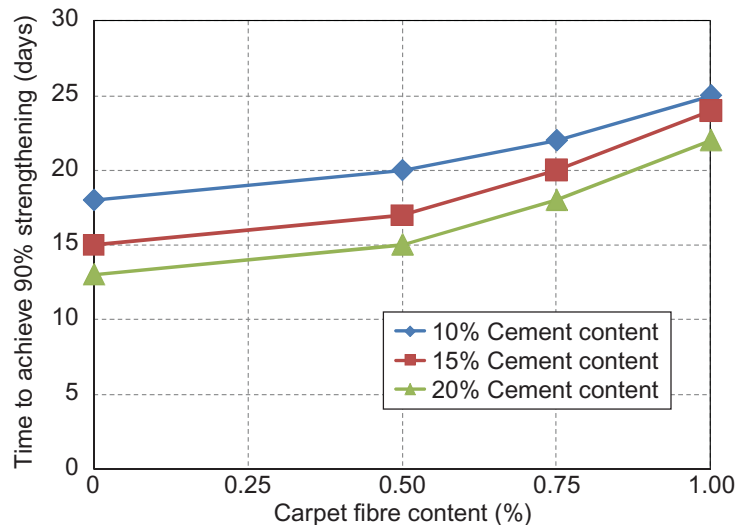

(a)

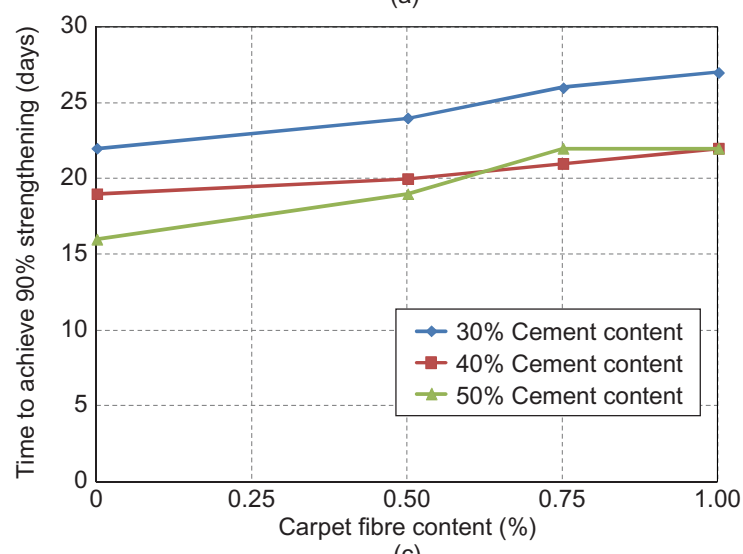

(c)

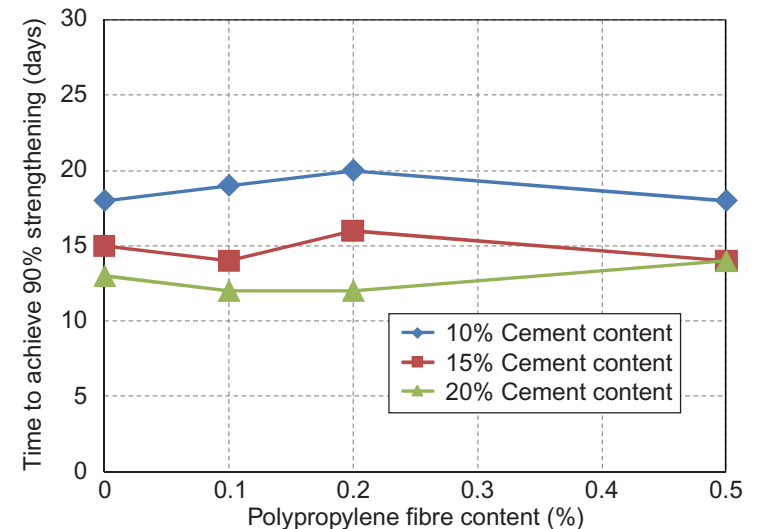

(b)

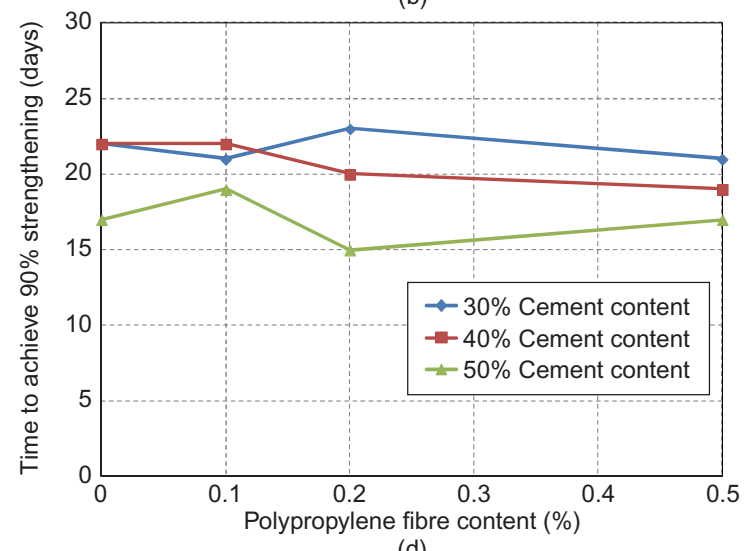

(d)

Figure 8. Variation of time required to achieve $90 \%$ strengthening with cement content and fibre content: (a) kaolinite treated with carpet fibre and cement; (b) kaolinite treated with polypropylene fibre and cement; (c) bentonite treated with carpet fibre and cement; (d) kaolinite treated with polypropylene fibre and cement

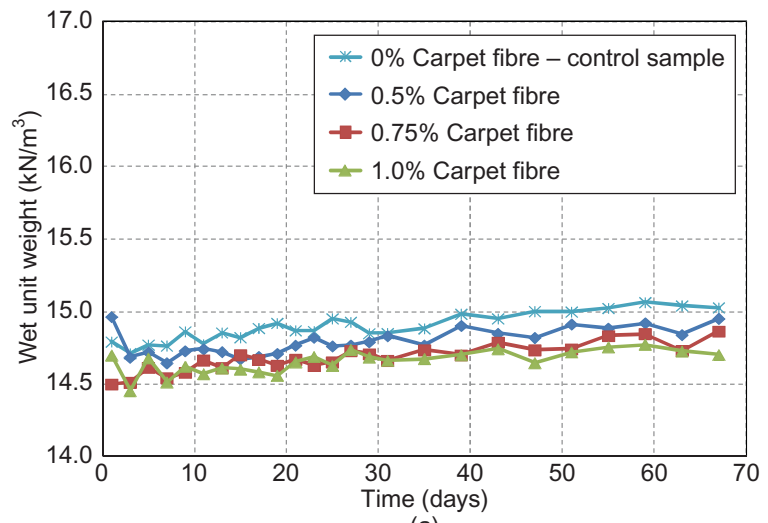

(a)

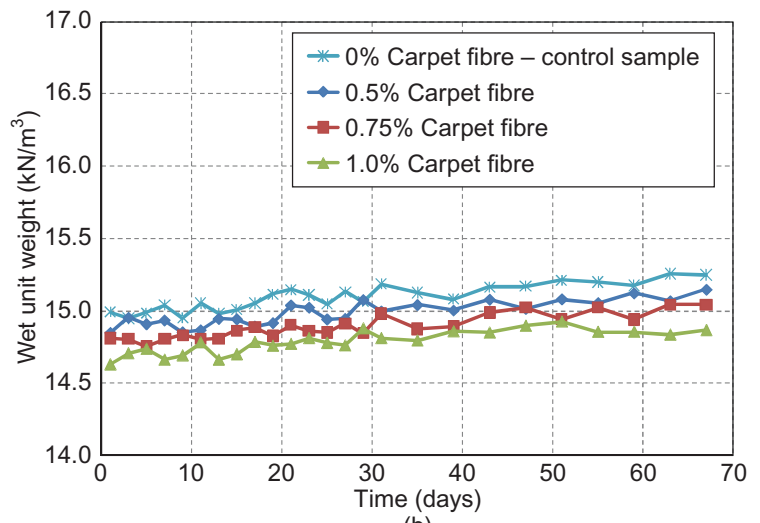

(b)

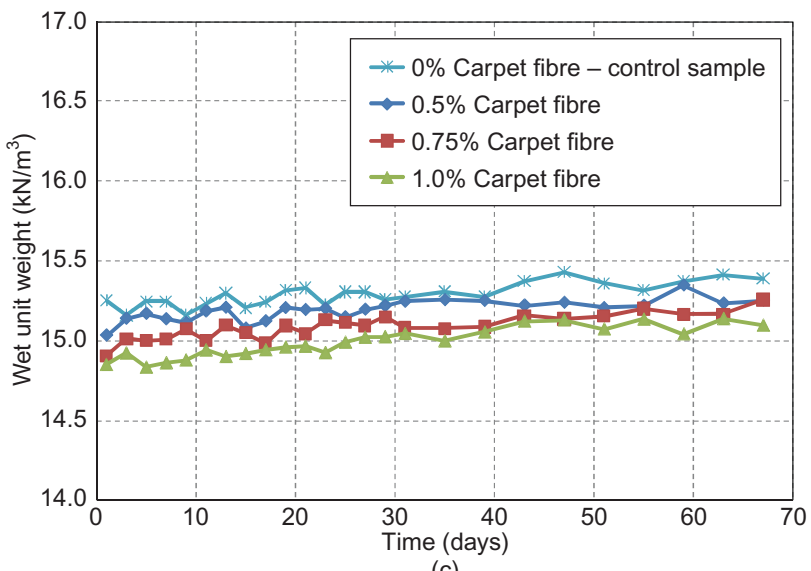

(c)

Figure 9. Variation of unit weight with curing time for carpet-reinforced kaolinite treated with: (a) $10 \%$ cement; (b) $15 \%$ cement; (c) $20 \%$ cement 


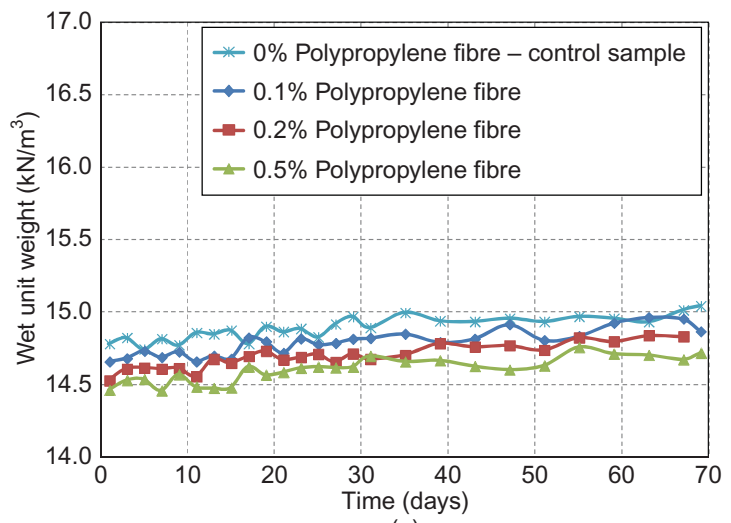

(a)

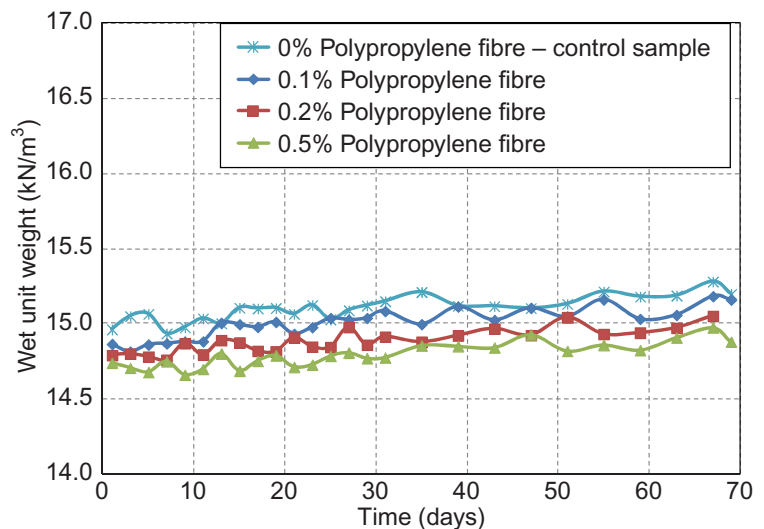

(b)

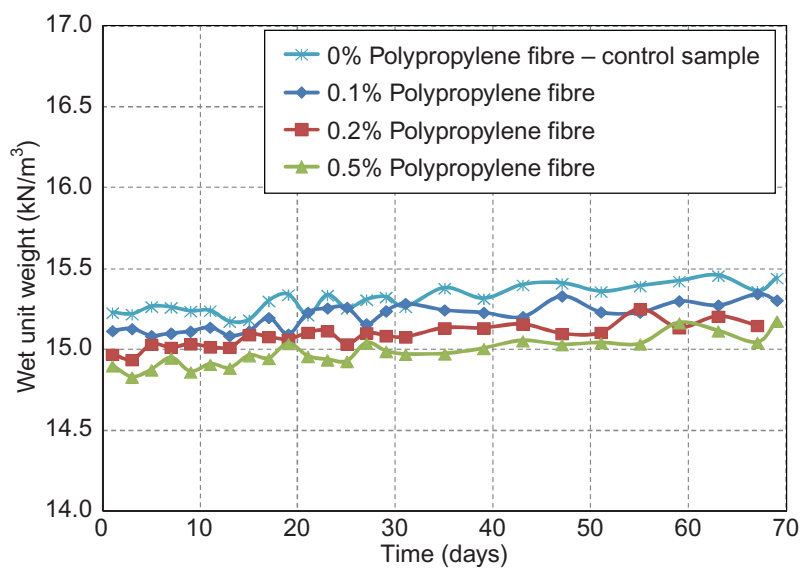

(c)

Figure 10. Variation of unit weight with curing time for polypropylene-reinforced kaolinite treated with: (a) $10 \%$ cement; (b) $15 \%$ cement; (c) $20 \%$ cement

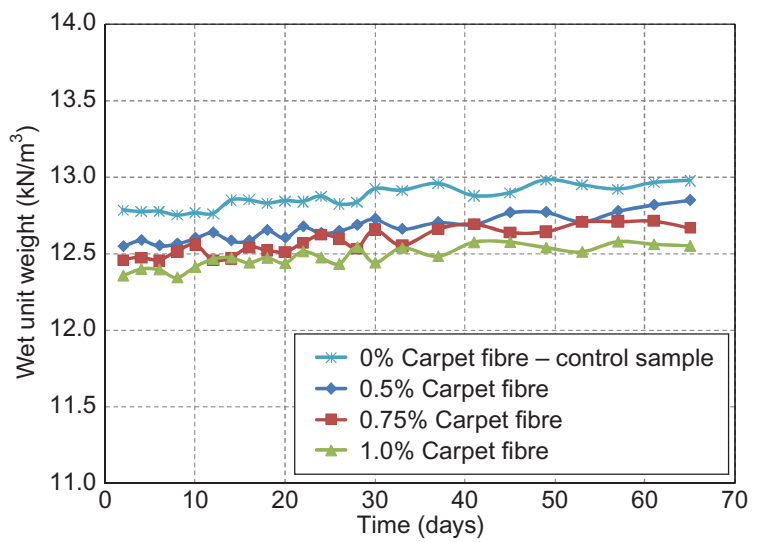

(a)

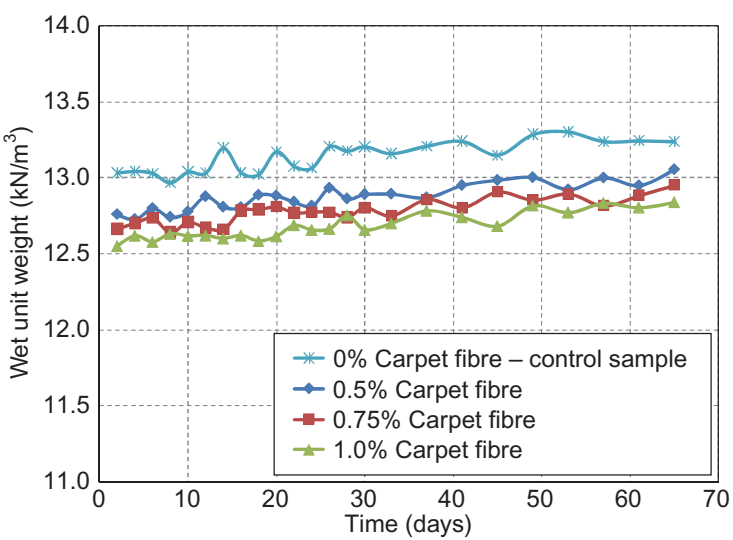

(b)

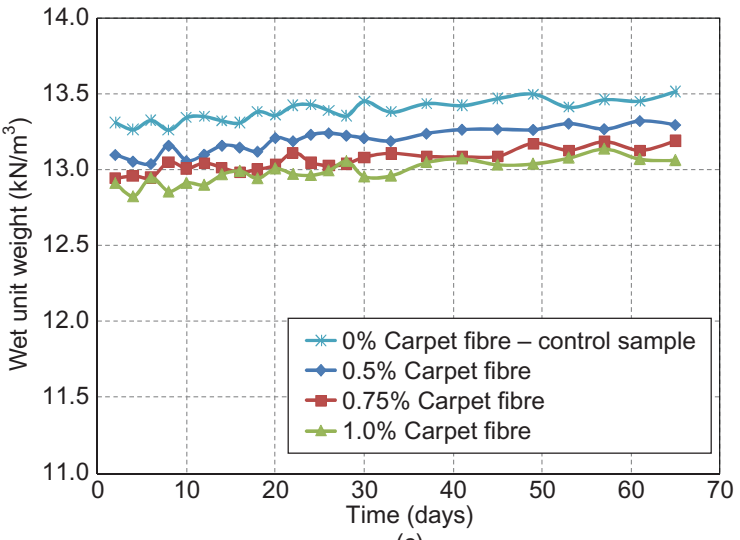

(c)

Figure 11. Variation of unit weight with curing time for carpet-reinforced bentonite treated with: (a) $30 \%$ cement; (b) $40 \%$ cement; (c) $50 \%$ cement 


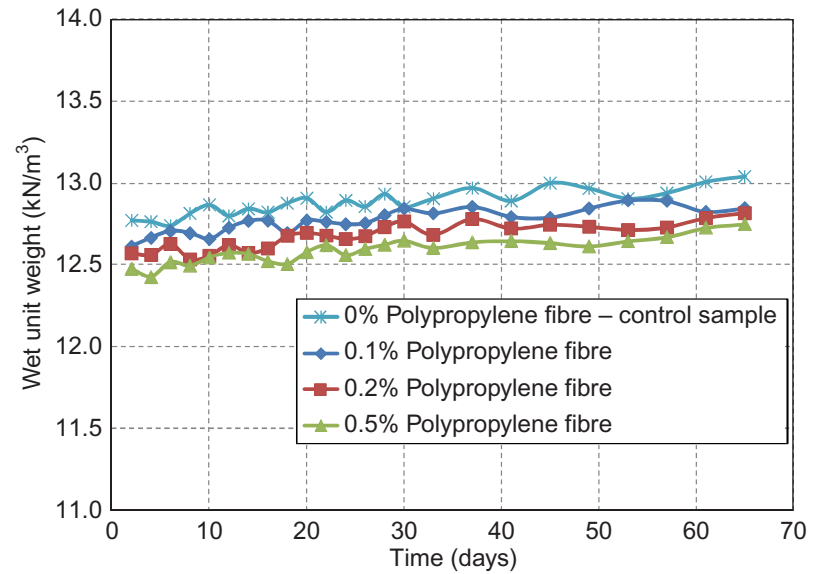

(a)

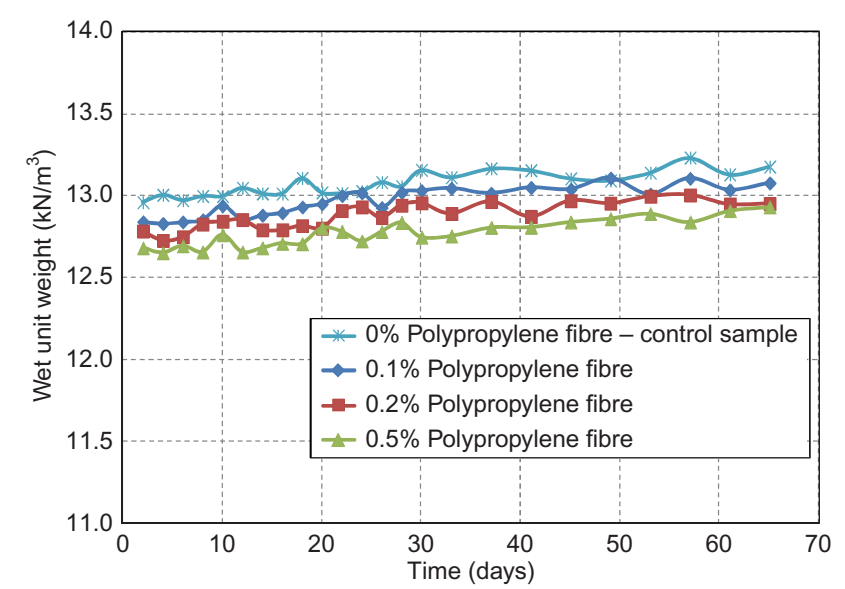

(b)

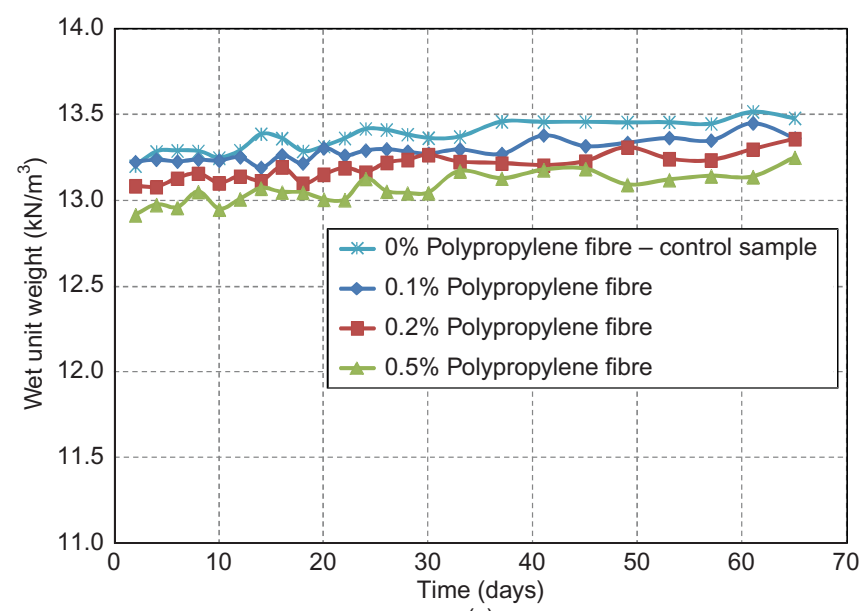

(c)

Figure 12. Variation of unit weight with curing time for polypropylene-reinforced bentonite treated with: (a) $30 \%$ cement; (b) $40 \%$ cement; (c) $50 \%$ cement

that the slight decrease in the unit weight of the samples due to the addition of fibres is because they have a lower unit weight than the soil or cement.

The small-strain shear modulus $G_{\max }\left(\gamma<10^{-5}\right)$ can be calculated using the equation

$$
G_{\max }=\rho V_{\mathrm{s}}^{2}
$$

where $G_{\max }$ is the small-strain shear modulus, $\rho$ is the density, $\gamma$ is the shear strain, and $V_{\mathrm{s}}$ is the shear wave velocity. Obviously, to predict the variations of $G_{\max }$ with curing time, the soil density and shear wave velocity are key parameters, and their variations should be considered carefully. Considering the recorded shear wave velocities and unit weights reported in Figures 4-12, the influence of fibre content, cement content and curing time on the small-strain shear modulus of cement-treated clay with fibres can be obtained from Figures 13-16.

As anticipated, the small-strain stiffness of the treated soil (both kaolinite and bentonite clays) increases when the cement content increases. The samples reinforced with polypropylene fibres show an increase in the stiffness with increasing fibre content. Figures 14 and 16 clearly indicate that, regardless of the percentage of cement employed, the addition of polypropylene fibres increases $G_{\max }$ of the cement-treated kaolinite and bentonite samples. This improvement is more noticeable when the cement content is more than $15 \%$ for kaolinite and $40 \%$ for bentonite. However, the small-strain stiffness of carpet-reinforced cement-treated clay decreases with fibre content, as shown in Figures 13 and 15. This may be a result of introducing a material that is more ductile than the cement-treated clay, and potentially does not engage very well with the surrounding matrix.

Since earthquakes travel through the ground before hitting a structure, the subsoil deposits play a significant role in determining the speed at which shear waves travel. Soft soil may increase the force of earthquakes applied to the superstructure, depending on the shear wave velocity of the soil deposit. Thus ground improvement methods such as cement treatment combined with fibre reinforcement may be considered to improve the dynamic soil properties. According to the available literature, in general, when the shear wave velocity of the supporting soil is less than $600 \mathrm{~m} / \mathrm{s}$, the effects of soil-structure interaction on the seismic response of structural systems are significant, particularly for moment resisting building frames. According to Fatahi et al. (2011) and Tabatabaiefar et al. (2012), the lateral deformation and inter-storey drifts of moment-resisting building frames under earthquakes increase when the shear wave velocity of the soil decreases. This may change the performance level of structures from life safe to near collapse or total collapse. Therefore 


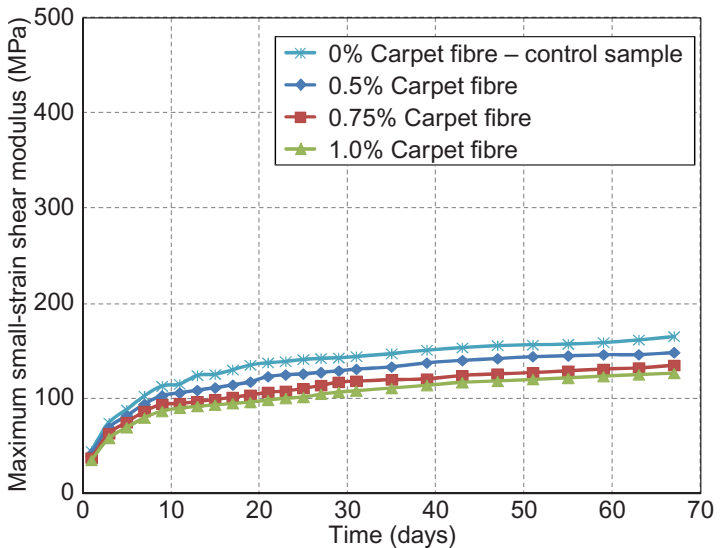

(a)

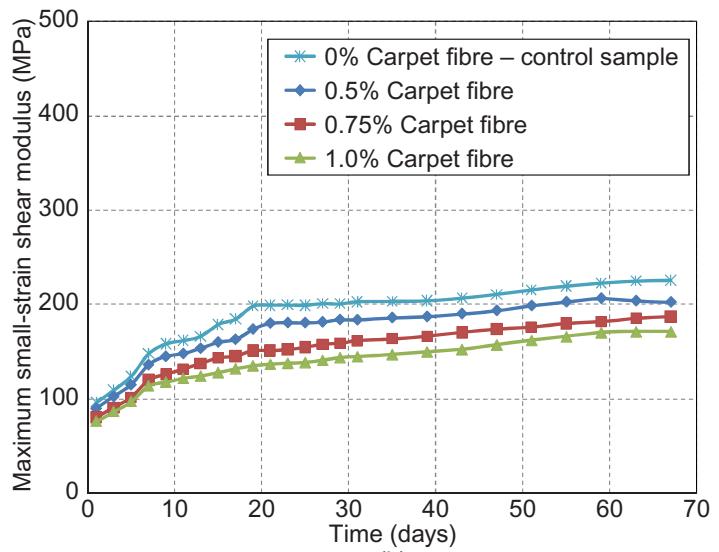

(b)

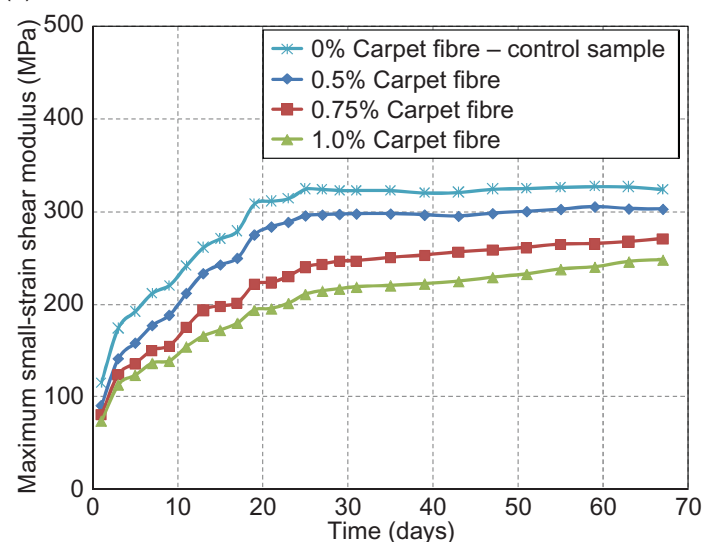

(c)

Figure 13. Variation of maximum small-strain shear modulus $\left(G_{\max }\right)$ with curing time for carpet-reinforced kaolinite treated with: (a) $10 \%$ cement; (b) $15 \%$ cement; (c) $20 \%$ cement

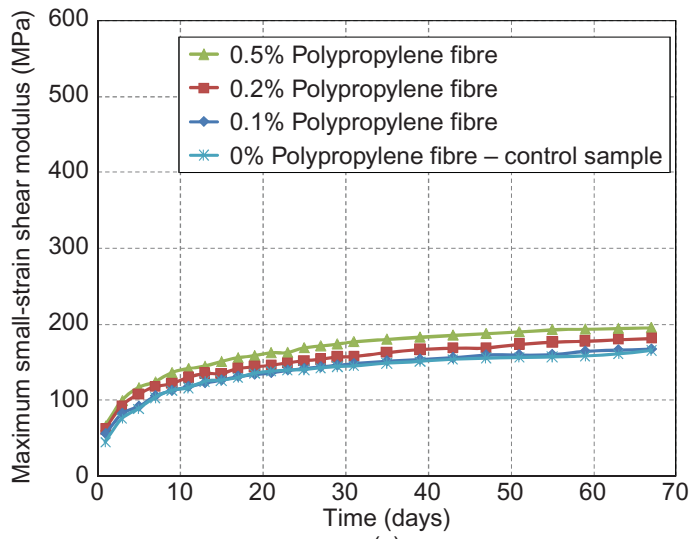

(a)

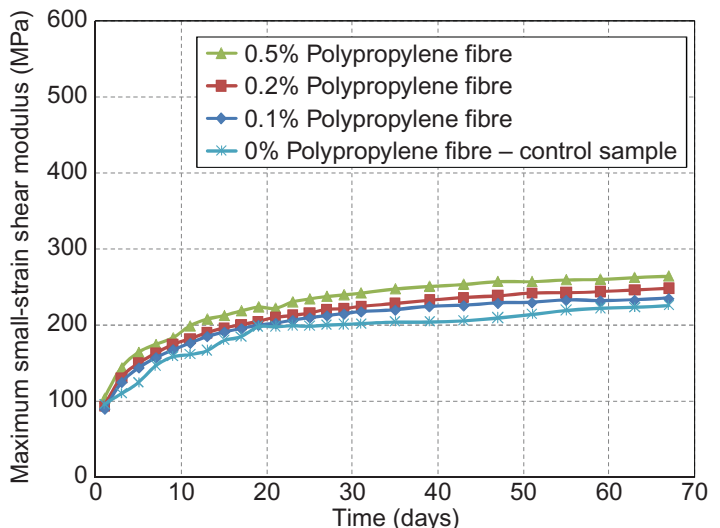

(b)

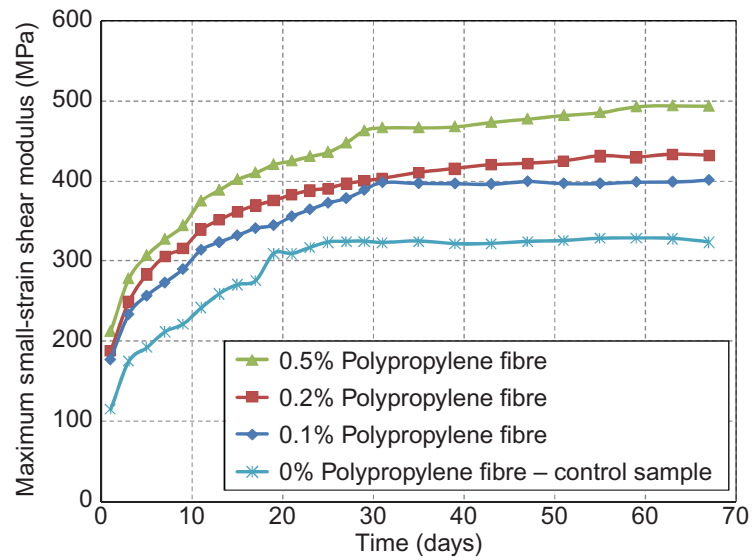

(c)

Figure 14. Variation of maximum small-strain shear modulus $\left(G_{\max }\right)$ with curing time for polypropylene-reinforced kaolinite treated with: (a) $10 \%$ cement; (b) $15 \%$ cement; (c) $20 \%$ cement 


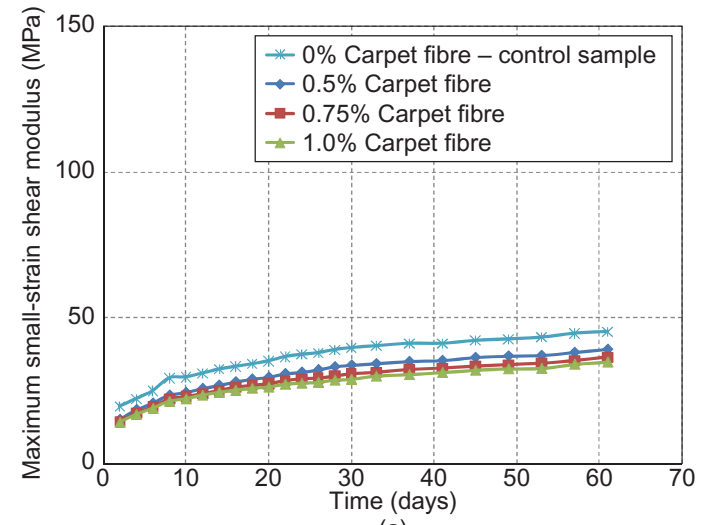

(a)

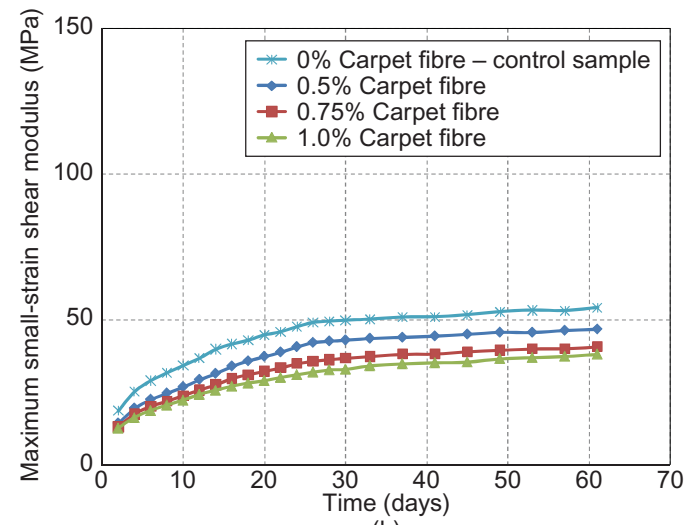

(b)

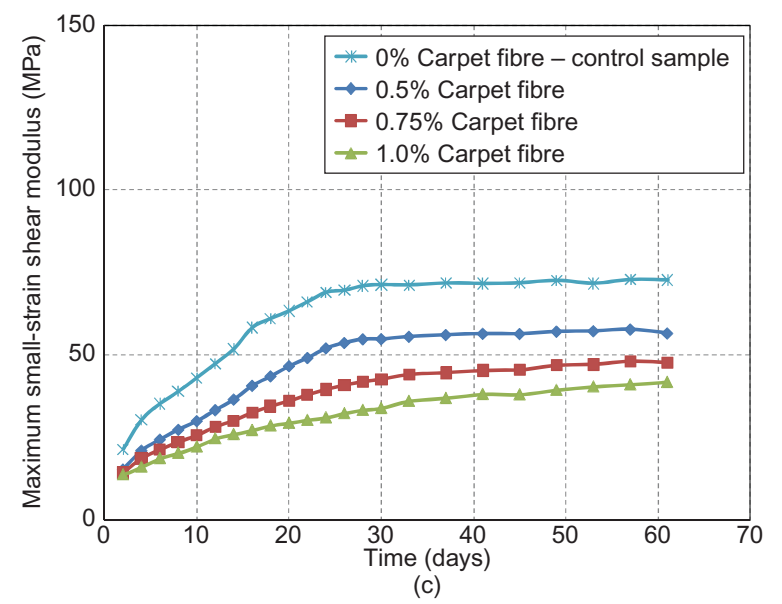

Figure 15. Variation of maximum small-strain shear modulus $\left(G_{\max }\right)$ with curing time for carpet-reinforced bentonite treated with: (a) 30\% cement; (b) $40 \%$ cement; (c) $50 \%$ cement

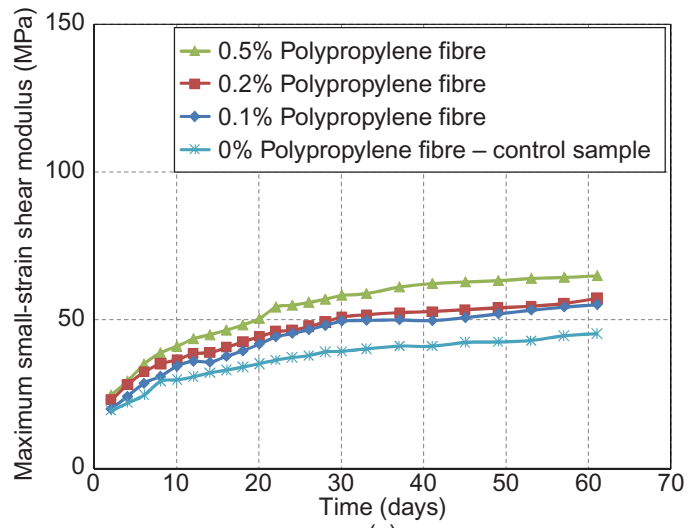

(a)

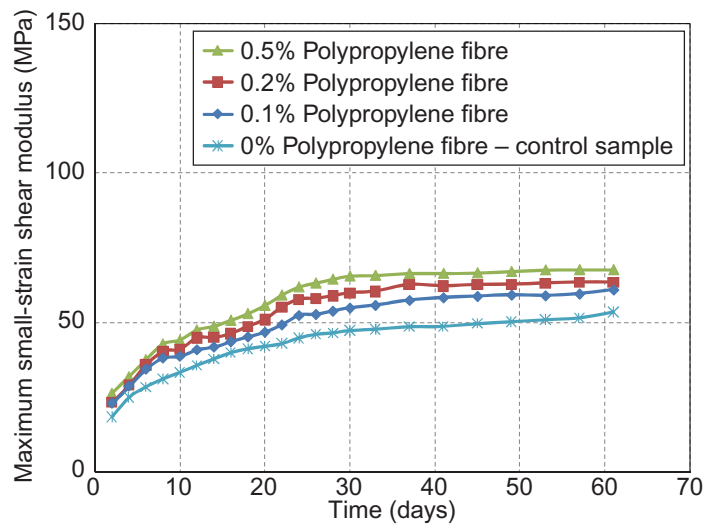

(b)

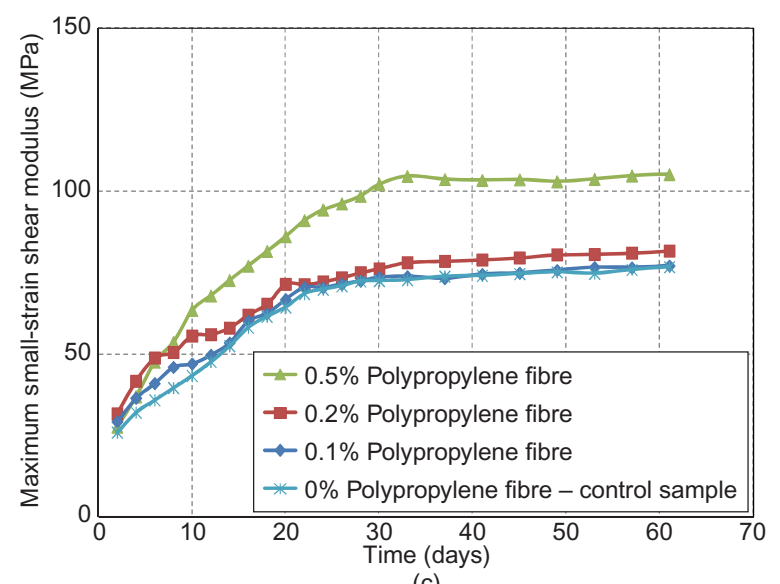

(c)

Figure 16. Variation of maximum small-strain shear modulus $\left(G_{\max }\right)$ with curing time for polypropylene-reinforced bentonite treated with: (a) $30 \%$ cement; (b) $40 \%$ cement; (c) $50 \%$ cement 
geotechnical engineers may consider ground improvement methods such as deep soil mixing to strengthen the ground and increase the shear wave velocity of the subsoil, minimising the lateral deformations of the structure.

The results obtained are of significant value, particularly for the design of ground improvement under dynamic loads such as earthquakes or high-speed rail, as the current literature does not address the influence of fibres on shear wave velocity or the small-strain properties of soft soils improved with deep soil mixing technology in conjunction with fibres to achieve the required design. Previous research has focused primarily on the strength gains associated with the introduction of a cementitious admixture to clay. Although the use of fibres in concrete columns is an accepted industry practice, research investigating the effects of fibres on the small-strain mechanical properties of soil-cement columns is limited. This study has covered the small-strain properties of clay samples mixed with various cement and fibre contents. The results show clearly that the addition of fibres can be adopted to reduce the cement content required for stabilising clayey soils, particularly in applications where the deformations under dynamic loads resulting from poor soil stiffness of the material are the primary challenges to overcome.

\section{CONCLUSIONS}

In this study, the effects of polypropylene and recycled carpet fibres on the shear wave velocity, unit weight and small-strain shear modulus of cement-treated kaolinite and bentonite clays have been investigated. A total of 126 specimens were prepared, and their properties were measured over more than two months.

The results show that the shear wave velocity of both kaolinite and bentonite clays increases with higher cement content and curing time, and the addition of carpet fibres contributes to a reduction of the shear wave velocity. The carpet fibre content influences the shear wave velocity more significantly when the soil is treated with higher cement contents. This may be due to the introduction of a material that is more ductile than the cement-treated clay, and potentially does not engage very well with the surrounding soil matrix. By contrast, the shear wave velocity increases when polypropylene fibres are used in the soil samples. The influence of polypropylene fibres on shear wave velocity is more pronounced for the kaolinite clay treated with higher cement contents. Similar to the cement-treated kaolinite, the addition of carpet fibres decreases the shear wave velocity of cement-treated bentonite, whereas polypropylene fibres increase it. The experimental results indicate that the time required to achieve $90 \%$ of the recorded shear wave velocity of cement-treated soil increases with carpet fibre content, but decreases with the cement content. This may be due to the absorption of water by the carpet fibres, resulting in a reduction of the water:cement ratio in the mix. However, the addition of polypropylene fibres has an insignificant effect on the hardening process, as polypropylene fibres do not absorb much water during the hydration process in the mix. Furthermore, the addition of fibres reduces the wet unit weight to some extent, whereas the unit weight of the treated soil increases slightly with higher cement content and age. As anticipated, the small-strain stiffness of the treated soil (for both kaolinite and bentonite clays) increases with cement content. The stiffness of samples reinforced with polypropylene increases with an increase in the fibre content.

\section{ACKNOWLEDGEMENTS}

The authors would like to thank V. Ng, Q. Trinh, Y. H. Wong and K. K. Tsang for their help in conducting the laboratory experiments as part of their undergraduate capstone projects at the University of Technology Sydney (UTS). They are also grateful to L. Bird of Carpet Recycling UK for providing recycled carpet fibres.

\section{REFERENCES}

Al-Akhras, N. M. (2003). Effect of fibres on unconfined compressive strength of clayey soil. Proceedings of the International Conference on Problematic Soils, Nottingham, UK, pp. 153-158.

Al-Refeai, T. (1991). Behavior of granular soils reinforced with discrete randomly oriented inclusions. Geotextiles and Geomembranes, 10, No. 4, 319-333.

Australian National Waste Report (2010). National Waste Policy Fact Sheet. Department of Environment, Heritage and the Arts. See http://www.environment.gov.au/settlements/waste/publications/pubs/ fs-national-waste-report-2010.pdf (accessed 01/09/2012).

Cai, Y., Shi, B., Ng, C. W. W. \& Tang, C. S. (2006). Effect of polypropylene fibre and lime admixture on engineering properties of clayey soil. Engineering Geology, 87, No. 3-4, 230-240.

Consoli, N. C., Casagrande, M. D. T., Prietto, P. \& Thome, A. (2003). Plate load test on fibre-reinforced soil. Journal of Geotechnical and Geoenvironmental Engineering, ASCE, 129, No. 10, 951-955.

Consoli, N. C., Foppa, D., Festugato, L. \& Heineck, K. S. (2007). Key Parameters for Strength Control of Artificially Cemented Soils. Journal of Geotechnical and Geoenvironmental Engineering, 133, No. 2, 197-205.

Craig, H. (2000). Soil Mechanics, Chapman \& Hall, London.

Edinçliler, A. \& Cagatay, A. (2013). Weak subgrade improvement with rubber fibre inclusions. Geosynthetics International, 20, No. 1, $39-46$.

Fam, M. A. \& Santamarina, J. C. (1996). Study of clay-cement slurries with mechanical and electromagnetic waves. Journal of Geotechnical Engineering, 122, No. 5, 365-373.

Fatahi, B., Khabbaz, H. \& Fatahi, B. (2012). Mechanical characteristics of soft clay treated with fibre and cement. Geosynthetics International, 19, No. 3, 252-262.

Fatahi, B., Tabatabaiefar, S. \& Samali, B. (2011). Performance based assessment of dynamic soil-structure interaction effects on seismic response of building frames. Geo-Risk 2011: Risk Assessment and Management, C. H. Juang, K. K. Phoon, A. J. Puppala, R. A. Green, and G. A. Fenton, Editors, Geotechnical Special Publication No. 224, ASCE, Reston, VA, USA, pp. 344-351.

Green Capital (2011). Business and Environment for Sustainable Economy. http://www.greencapital.org.au/issues/waste.html. Accessed 20 August 2011.

Heineck, K. S., Coop, M. R. \& Consoli, N. C. (2005). Effect of microreinforcement of soils from very small to large shear strain. Journal of Geotechnical and Geoenvironmental Engineering, 131, No. 8, 1024-1033.

Jiang, H., Cai, Y. \& Liu, J. (2010). Engineering properties of soils reinforced by short discrete polypropylene fiber. Journal of Materials in Civil Engineering, 22, No. 12, 1315-1322.

Kumar, A. \& Kaur, A. (2012). Model tests of square footing resting on fibre-reinforced sand bed. Geosynthetics International, 19, No. 5, 385-392. 
Lorenzo, G. A. \& Bergado, D. T. (2004). Fundamental parameters of cement-admixed clay: new approach. Journal of Geotechnical and Geoenvironmental Engineering, 130, No. 10, 1-9.

Michalowski, R. L. \& Cermak, J. (2003). Triaxial compression of sand reinforced with fibres. Journal of Geotechnical and Geoenvironmental Engineering, 129, No. 2, 125-136.

Miller, C. J. \& Rifai, S. (2004). Fibre reinforcement for waste containment soil liners. Journal of Environmental Engineering, 130, No. 8, 981-985.

Miraftab, M. \& Lickfold, A. (2008). Utilization of carpet waste in reinforcement of substandard soils. Journal of Industrial Textiles, 38, No. 2, 167-174.

Moncrieff, R. W. (1975). Man-Made Fibres, Newnes-Butterworths, London, UK.

Morel, J. C. \& Gourc, J. P. (1997). Mechanical behavior of sand reinforced with mesh elements. Geosynthetics International, 4, No. 5, 481-508.

Murray, H. H. (1999). Applied clay mineralogy today and tomorrow. Clay Minerals, 34, No. 1, 39-49.

Piriyakul, K. \& Pochalard, S. (2012). Stiffness of soil cement fly ash by means of shear wave velocity. Proceedings of the ISSMGE-TC211
International Symposium on Ground Improvement, Brussels, Belgium, pp. II451-II458.

Sahin, A. (2009). Freezing-Thawing Behaviour of Fine-Grained Soils Reinforced with Polypropylene Fibres. Technical Vocational School of Higher Education, Ataturk University, Erzurum, Turkey.

Tabatabaiefar, H. R., Fatahi, B. \& Samali, B. (2012). An empirical relationship to determine lateral seismic response of mid-rise building frames under influence of soil-structure interaction. The Structural Design of Tall and Special Buildings, http://dx.doi.org/ 10.1002/tal.1058.

Trhlíková, J., Mašín, D. \& Boháč, J. (2012). Small-strain behaviour of cemented soils. Géotechnique, 62, No. 10, 943-947.

Wang, Y., Zureick, A. H., Cho, B. S. \& Scott, D. E. (1994). Properties of fibre reinforced concrete using recycled fibres from carpet industrial waste. Journal of Material Science, 29, No. 16, 4191-4199.

Wang, Y. (1999). Utilization of recycled carpet waste fibres for reinforcement of concrete and soil. Polymer-Plastic Technology Engineer, 38, No. 3, 533-546.

Yetimoglu, T., Inanir, M. \& Inanir, O. E. (2005). A study on bearing capacity of randomly distributed fibre-reinforced sand fills overlying soft clay. Geotextiles and Geomembranes, 23, No. 2, 174-183.

The Editor welcomes discussion on all papers published in Geosynthetics International. Please email your contribution to discussion@geosynthetics-international.com by 15 February 2014. 